\title{
Randomized study of surgical isolation of the pulmonary veins for correction of permanent atrial fibrillation associated with mitral valve disease
}

\author{
Álvaro Albrecht, MD, ${ }^{\mathrm{a}}$ Renato A. K. Kalil, MD, PhD, ${ }^{\mathrm{a}, \mathrm{c}}$ Luciana Schuch, $\mathrm{MD},{ }^{\mathrm{a}}$

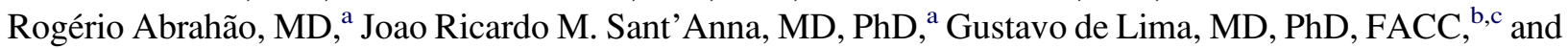 \\ Ivo A. Nesralla, MD, $\mathrm{PhD}^{\mathrm{a}}$
}

\begin{abstract}
Objective: Chronic permanent atrial fibrillation is often due to mitral valve disease. The Cox maze procedure is the gold standard for treating this arrhythmia. Simpler techniques and ablation methods should have their efficacy tested in clinical practice. Our objective was to evaluate the effectiveness of surgical pulmonary vein isolation as compared with the Cox maze procedure.
\end{abstract}

\begin{abstract}
Methods: Sixty patients were randomly assigned to control group, modified maze group (Cox maze III), and surgical isolation of the pulmonary veins (SPVI) group from July 1999 to October 2004. All patients had mitral valve lesions treated concomitantly. Preoperative characteristics were similar between groups.

Results: There were 4 deaths: 3 in the Cox maze group and 1 in the SPVI group $(P=.31)$. The Cox maze group presented longer times of extracorporeal circulation and myocardial ischemia $(P<.001)$. The relative risk of late postoperative development of atrial fibrillation was 0.07 in the SPVI group $(P<.001 ; 95 \%$ confidence intervals: $0.02-0.27)$ and 0.195 in the Cox maze group ( $P=.002 ; 95 \%$ confidence intervals: $0.07-0.56)$ as compared with the control group. No difference was found between the SPVI and Cox maze groups concerning prevention of atrial fibrillation recurrence (relative risk: $0.358 ; P=.215 ; 95 \%$ confidence intervals: $0.08-1.67$ ).
\end{abstract}

Conclusions: The modified Cox maze procedure and surgical pulmonary vein isolation were similarly effective in restoring sinus or regular rhythm in permanent atrial fibrillation associated with mitral valve disease. These results favor the adoption of surgical isolation as a preferable technique, simpler and equally effective in controlling atrial fibrillation. The results also can bring further information for understanding the mechanisms involved in origins and treatment of chronic permanent atrial fibrillation.

Atrial fibrillation $(\mathrm{AF})$ is the commonest sustained arrhythmia, ${ }^{1}$ present in $0.4 \%$ of the general population and in $10 \%$ of the population over 60 years of age. Although the diagnosis is simple, its treatment is complex and long term, with unsatisfactory optimal outcomes. Its prevalence increases evenly with aging. ${ }^{2,3}$ It is an independent risk factor associated with a $50 \%$ to $90 \%$ increase in the mortality risk, both in male and in female subjects. ${ }^{4}$ It is often associated with advanced mitral valvular lesions. AF is the leading cause of embolic episodes, $75 \%$ of which are cerebrovascular. ${ }^{5,6}$ The most feared complication of AF is systemic thromboembolism, which can lead to death or severe sequelae. Multicenter studies show a $45 \%$ to $86 \%$ reduction in the

From the Departments of Cardiovascular Surgery ${ }^{\mathrm{a}}$ and Electrophysiology, ${ }^{\mathrm{b}}$ Instituto de Cardiologia do Rio Grande do Sul/Fundação Universitária de Cardiologia (IC/FUC), and the Department of Cardiology, ${ }^{c}$ Universidade Federal de Ciências da Saúde de Porto Alegre (UFCSPA), Porto Alegre, Brazil.

Financial support in part by Brazilian Ministry of Education: Agency CAPES/Program PROSUP and Research Foundation of Rio Grande do Sul, (FAPERGS).

Received for publication Nov 21, 2008; revisions received April 9, 2009; accepted for publication April 23, 2009.

Address for reprints: Unidade de Pesquisa do IC/FUC, Dr Álvaro Albrecht, Avenida Princesa Isabel, 370 Santana-Porto Alegre, RS-90620-001 (E-mail: editoracao-pc@cardiologia.org.br/ alvaroalbrecht@hotmail.com).

J Thorac Cardiovasc Surg 2009;138:454-9

$0022-5223 / \$ 36.00$

Copyright (c) 2009 by The American Association for Thoracic Surgery

doi: $10.1016 /$ j.jtcvs.2009.04.023 frequency of thromboembolic events with the use of warfarin/aspirin, the annual incidence of embolic events remaining between $0.4 \%$ and $3.5 \%$, associated with the annual incidence of deadly or severe hemorrhages of up to $2.5 \%$ with warfarin. ${ }^{7-10}$ The antiarrhythmic drugs are not tolerated in $10 \%$ to $15 \%$ of patients owing to side effects and often cause potentially deadly proarrhythmic effects as well. ${ }^{11}$

The correction of a structural cardiac lesion can contribute to the treatment of AF. ${ }^{12}$ However, recent data show that persistent $\mathrm{AF}$ is the most important risk factor for late cerebrovascular accident (CVA) after mitral valve replacement. ${ }^{13}$ The same study showed that reversion to sinus rhythm through the maze procedure virtually eliminated the risk of late CVA. Thrombohemorrhagic events are less frequent in patients in sinus rhythm after correction of $\mathrm{AF}$ associated with mitral valve lesions. ${ }^{14}$ In patients who receive surgical treatment for $\mathrm{AF}$ and achieve reversion to sinus rhythm, the duration of therapy with oral anticoagulants remains controversial.

In 1991 Cox $^{15}$ reported results with the maze technique, which showed the best rates of cure of AF until then, becoming the gold standard for comparisons. ${ }^{16}$ This technique was modified by others, and in some reports cryoablation was not used. ${ }^{17,18}$ More recently, Fieguth, Wahlers, and Borst ${ }^{19}$ and Haissaguerre and colleagues ${ }^{20}$ demonstrated that pulmonary veins, inside the left atrium, are the main focus of triggering and maintaining paroxysmal AF. In this situation and on the 

Abbreviations and Acronyms
$\mathrm{AF}=$ atrial fibrillation
$\mathrm{CI}=$ confidence intervals
$\mathrm{CVA}=$ cerebrovascular accident
$\mathrm{ECC}=$ extracorporeal circulation
$\mathrm{ECG}=$ electrocardiogram
SPVI $=$ surgical isolation of pulmonary veins

basis of our previous experience with the maze procedure, we devised a simpler procedure, basically cut and sew, which actually is the part of the maze operation that isolates the pulmonary veins, added with resection of the atrial appendix and a perpendicular incision between the circular incision and the mitral valvular ring (to prevent left atrial flutter). ${ }^{21,22}$ An initial randomized study with 30 patients was performed, which indicated that the technique of surgical isolation of the pulmonary veins (SPVI) may show results as promising as those of the maze procedure in the correction of $\mathrm{AF}$ associated with structural cardiac lesions. ${ }^{23}$ The sample of the previous study was doubled to determine with greater statistical power which technique for treatment of $\mathrm{AF}$ associated with structural cardiac disease might be more effective.

\section{METHODS}

Sixty consecutive patients with permanent $\mathrm{AF}$ and fulfilling clinical and hemodynamic criteria for elective mitral valvular correction were selected for the study. Exclusion criteria were permanent AF of less than 6 months' duration, age under 18 or over 79 years, left ventricular ejection fraction below $20 \%$, ongoing pregnancy at the time of surgery, reoperations, presence of intrapericardial adhesions, reference from a cardiologist to any $\mathrm{AF}$ correction technique, and patient nonacceptance of the Free Informed Consent
Form. The present study was approved by the Ethical Board of the Instituto de Cardiologia do Rio Grande do Sul/Fundação Universitária de Cardiologia on August 9, 1999.

This was a randomized controlled clinical trial. The patients were selected from June 1999 to October 2004. As techniques for treatment of $\mathrm{AF}$ became more popular, many patients in this period had already been referred to surgery with indication from the cardiologist to receive specific treatment for AF combined with mitral valve surgery. Those many cases were excluded from randomization and this situation prolonged the duration of the study. The population was randomized into three groups: (1) valvular correction plus a simplified technique of surgical isolation of the pulmonary veins (SPVI group), (2) valvular correction plus modified maze procedure (Cox maze III) with no use of cryoablation (maze group), or (3) no procedure associated with mitral valve correction (control group).

After signing a free consent form, the patients were submitted to an electrocardiogram (ECG) and Doppler unidimensional and bidimensional echocardiogram and referred for surgery. All patients were operated on by two main surgeons. Immediately before the beginning of the operation, a sealed envelope was opened to indicate the procedure to be performed. After anesthetic induction, patients were subjected to median sternotomy and opening of the pericardium. Extracorporeal circulation (ECC) was instituted by arterial cannulation into the ascending aorta and venous cannulation with angled cannulas into the venae cavae, which were mobilized. Aortic clamping and routine infusion of antegrade crystalloid hypothermic cardioplegic solution were done. Body temperature was maintained at $32^{\circ} \mathrm{C}$ to $34^{\circ} \mathrm{C}$ during ECC. A left longitudinal atriotomy was performed in all patients. In the control group, the valve was corrected at this point. The maze group was subjected to the Cox maze III operation, ${ }^{15,16}$ modified, with no use of cryoablation, which was replaced by wide dissection at the area of the coronary sinus and cauterization of adjacent tissues. Before complete atrial wall suture, the mitral valve was corrected or replaced. In the SPVI group, the atriotomy was extended so as to enclose all four pulmonary veins. At this point, the mitral valve was treated. A perpendicular incision was performed from the extended atriotomy border to the annulus of the mitral valve, dissecting the coronary sinus and performing electrocauterization as described previously. ${ }^{17}$ The left atrial appendix was always excised, in both treatment groups. After atrial suture with 3-0 monofilament polypropylene in a single layer, the other valves were corrected if necessary. Amiodarone or any other antiarrhythmic drugs were not routinely used during the operation or in the intensive care unit.

TABLE 1. Clinical characteristics

\begin{tabular}{|c|c|c|c|c|c|}
\hline Characteristics & $\operatorname{SPVI}(\mathbf{n}=20)$ & $\operatorname{Maze}(n=20)$ & Control $(n=20)$ & Total $(n=60)$ & $P$ value \\
\hline Age (y) & $55.1 \pm 9.2$ & $51.7 \pm 12.4$ & $51.3 \pm 14.7$ & $53 \pm 14.2$ & $.556^{*}$ \\
\hline Female sex $(\%)$ & 70 & 75 & 50 & 65 & $.318 \dagger$ \\
\hline Duration of AF (mo) & $31.78 \pm 31.6$ & $35.4 \pm 38.5$ & $24.6 \pm 32.0$ & $30.6 \pm 35.7$ & $.346 \ddagger$ \\
\hline Ejection fraction & $62.1 \pm 11.3$ & $64.3 \pm 7.1$ & $63.3 \pm 7.0$ & $63.2 \pm 8.5$ & $.811^{*}$ \\
\hline Left atrium $(\mathrm{cm})$ & $5.32 \pm 0.8$ & $5.99 \pm 1.6$ & $6.21 \pm 1.16$ & $5.84 \pm 1.16$ & $.273^{*}$ \\
\hline NYHA & $2.85 \pm 0.67$ & $2.75 \pm 0.71$ & $2.95 \pm 0.76$ & $2.85 \pm 0.70$ & $.679 *$ \\
\hline I ( $\%)$ & - & - & 5 & 1.7 & $.560 \dagger$ \\
\hline II $(\%)$ & 30.0 & 40.0 & 15.0 & 28.3 & \\
\hline III $(\%)$ & 55.0 & 45.0 & 60.0 & 53.3 & \\
\hline IV (\%) & 15.0 & 15.0 & 20.0 & 16.7 & \\
\hline Mitral lesion (\%) & & & & & $.397 \dagger$ \\
\hline Stenosis & 55.0 & 45.0 & 25.0 & 41.7 & \\
\hline Insufficiency & 35.0 & 45.0 & 55.0 & 45.0 & \\
\hline Mixed lesion & 10.0 & 10.0 & 20.0 & 13.3 & \\
\hline Etiology $(\%)$ & & & & & $.930 \dagger$ \\
\hline Rheumatic & 80.0 & 75.0 & 70.0 & 75.0 & \\
\hline Degenerative & 20 & 25.0 & 30.0 & 25.0 & \\
\hline
\end{tabular}

$S P V I$, Surgical isolation of pulmonary veins; $A F$, atrial fibrillation; $N Y H A$, New York Heart Association functional class. Data appear as mean \pm standard deviation and frequency (\%). *Analysis of variance; $\dagger \chi^{2}$ test; $\ddagger$ Kruskal-Wallis test. 
TABLE 2. Descriptive data according to surgical techniques

\begin{tabular}{|c|c|c|c|c|c|}
\hline & $\operatorname{SPVI}(n=20)$ & $\operatorname{Maze}(n=20)$ & Control $(\mathbf{n}=\mathbf{2 0})$ & Total $(n=60)$ & $P$ value \\
\hline Mitral correction (\%) & & & & & $.236 \dagger$ \\
\hline Valvuloplasty & 60 & 55 & 60 & 58.3 & \\
\hline Bioprosthesis & 30 & 40 & 15 & 28.3 & \\
\hline Mechanical prosthesis & 10 & 5 & 25 & 13.3 & \\
\hline Associated surgery (\%) & 25 & 10 & 25 & 20 & $.392 \dagger$ \\
\hline Duration of ECC (min) & $99.85 \pm 23.8^{\mathrm{a}}$ & $122.95 \pm 21.0^{\mathrm{b}}$ & $62.0 \pm 23.8^{\mathrm{c}}$ & $94.93 \pm 33.9$ & $<.001 *$ \\
\hline Duration of ischemia (min) & $74.75 \pm 19.2^{\mathrm{a}}$ & $78.50 \pm 15.9^{\mathrm{a}}$ & $45.10 \pm 21.1^{\mathrm{b}}$ & $66.12 \pm 23.9$ & $<.001 *$ \\
\hline Rhythm at discharge (\%) & & & & & $<.001 \dagger$ \\
\hline Sinus/atrial & 80 & 75 & 15 & 56.7 & \\
\hline PAF/flutter & 20 & 25 & 85 & 43.3 & \\
\hline
\end{tabular}

SPVI, Surgical isolation of pulmonary veins; $E C C$, extracorporeal circulation; $P A F$, permanent atrial fibrillation. Data appear as mean \pm standard deviation and frequency (\%), *Analysis of variance; $\dagger \chi^{2}$ test. Noncoincidental index letters $(a, b, c)$ represent statistically significant differences through the Duncan procedure of multiple comparisons.

Blood and blood products were routinely used to maintain hematocrit value over $30 \%$, and there were no differences between groups regarding transfusions.

Before hospital discharge, all patients who were not in regular rhythm were subjected to electrical cardioversion and their rhythm maintained with oral amiodarone if it reverted to sinus rhythm. Two months after the operation, the patients returned to a specific clinic to be subjected to an ECG and a clinical evaluation. Afterward, the patients were to return to the clinic for a new ECG, echocardiogram, and treadmill stress test every 6 months for 24 months, after which they were followed up on a 6-month basis with ECGs. The patients who failed to return were contacted by telephone. However, the rhythm was always evaluated by ECG. The medications prescribed by the assistant cardiologists were not modified.

All obtained data were fed into Microsoft Excel XP (Microsoft Corporation, Redmond, Wash) and processed with SPSS system for statistics (SPSS 13.0 for Windows, SPSS Inc, Chicago, Ill) software. Continuous variables were expressed as mean \pm standard deviation. Comparisons were made with the $\chi^{2}$ test for categorical variables. Cornfield analysis and Fisher's exact tests were also used as indicated. The Kruskal-Wallis test, analysis of variance, and the Duncan procedure of multiple comparisons for continuous variables were also used. Kaplan-Meier curves were compared by the logrank test.

A critical alpha of .05 was used for these comparisons to be considered as statistically significant.

\section{RESULTS}

Table 1 shows that the groups were statistically similar in all variables analyzed before the operation. The mean age of patients undergoing surgery was $53 \pm 14.2$ years, and $66.7 \%$ were female. Mean New York Heart Association functional classification was $2.85 \pm 0.70$. Mitral stenosis occurred in $41.7 \%$, mitral insufficiency in $45 \%$, and mixed mitral lesion in $13.3 \%$ of the patients. The prevalence of rheumatic disease was $75 \%$, and $18.3 \%$ of the patients had previous cerebral thromboembolism (Table 1).

By analyzing the mitral correction technique, we observed that valvuloplasty was the most common technique used $(58.3 \%$ of the patients), followed by mitral bioprosthesis $(28.3 \%)$ and mechanical mitral prosthesis $(13.3 \%)$ (Table 2). Aortic valvuloplasty was performed in 3.3\% of the patients, tricuspid valvuloplasty in $11.7 \%$, and atrioseptoplasty in $1.7 \%(P=.312$ for differences between the groups). The mean time of ECC was about 23 minutes longer in the maze group than in the SPVI group $(P<.001)$ because of the time required for performing the incisions and sutures in the right atrium, done on the beating heart. However, the time of myocardial ischemia did not differ between these groups; it differed only as compared with the control group (Table 2).

P wave morphology may be deformed after the maze procedure. Given the ECG difficulty of characterizing the sinus rhythm in this group, we considered both sinus and atrial rhythm as success. At hospital discharge, the SPVI group had the highest success rate, with an $80 \%$ rate of reversion to sinus rhythm $(P<.001)$. The maze group achieved a success rate of $75 \%$, and in the control group only $15 \%$ of the

TABLE 3. Patient follow-up

\begin{tabular}{|c|c|c|c|c|c|}
\hline Characteristics & $\operatorname{SPVI}(n=20)$ & $\operatorname{Maze}(n=20)$ & Control $(n=20)$ & Total $(n=60)$ & $P$ value \\
\hline Time (mo) & $39.18 \pm 19.3$ & $31.35 \pm 23.4$ & $36.1 \pm 16.9$ & $35.54 \pm 20$ & $.468^{*}$ \\
\hline Rhythm (\%) & & & & & $<.001 \dagger$ \\
\hline Sinus & $90 \%$ & $85 \%$ & $30 \%$ & $68.3 \%$ & \\
\hline PAF & $10 \%$ & $15 \%$ & $70 \%$ & $31.7 \%$ & \\
\hline NYHA & $1.20 \pm 0.52$ & $1.35 \pm 0.74$ & $1.45 \pm 0.68$ & $1.33 \pm 0.65$ & $.486^{*}$ \\
\hline I $(\%)$ & 85 & 80 & 65 & 76.7 & $.346 \dagger$ \\
\hline II $(\%)$ & 10 & 5 & 25 & 13.3 & \\
\hline III $(\%)$ & 5 & 15 & 10 & 10 & \\
\hline Mortality (\%) & 5 & 15 & - & 3.9 & $.153 \dagger$ \\
\hline
\end{tabular}

$S P V I$, Surgical isolation of pulmonary veins; $P A F$, permanent atrial fibrillation; NYHA, New York Heart Association functional class. Data appear as mean \pm standard deviation and frequency $(\%) * *^{*}$ Analysis of variance; ANOVA; $\dagger \chi^{2}$ test. 

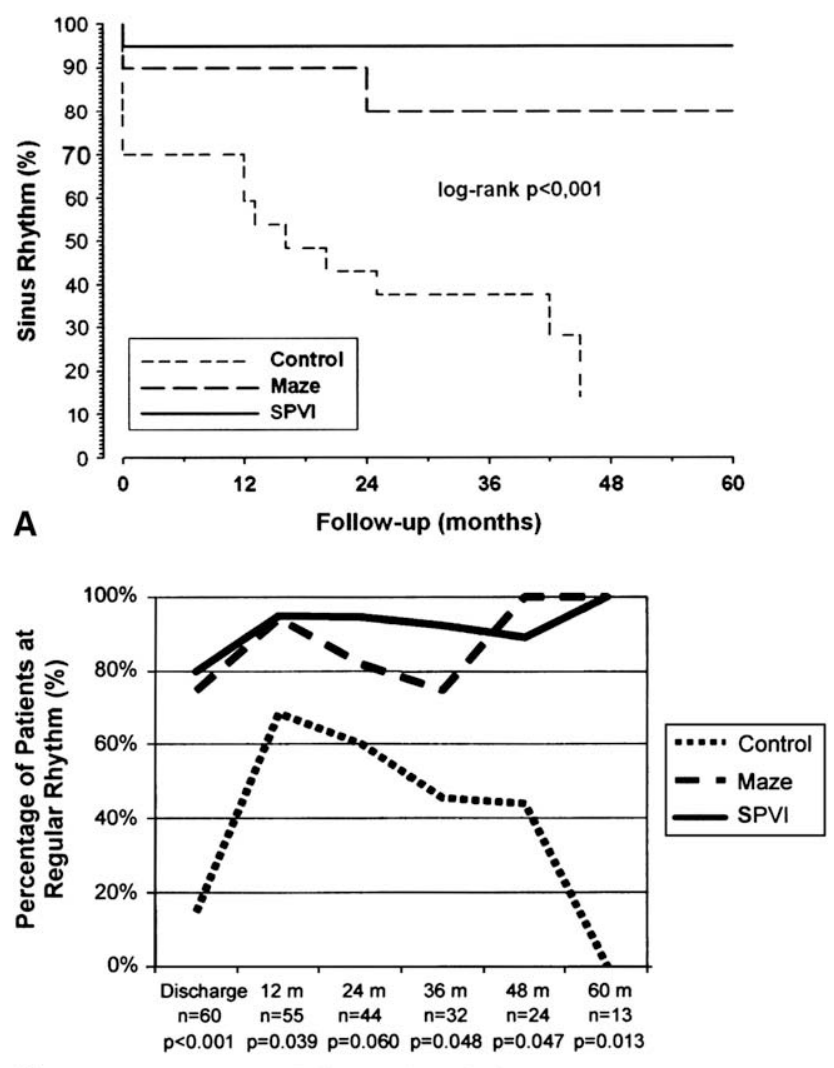

B

Follow-up (months)

FIGURE 1. A, Kaplan-Meier curve showing the number of patients at sinus rhythm as a function of time, according to surgical technique. B, Patient follow-up according to presence of regular rhythm at 12-month intervals.

patients were discharged in sinus rhythm $(P<.001)$. After a mean follow-up of $35 \pm 20$ months, with no difference between the groups, the SPVI group had the highest rate of conversion to sinus rhythm ( $90 \%$ of the patients), followed by the maze group ( $85 \%)$. The control group had a $30 \%$ rate of sinus rhythm $(P<.001)$ (Table 3; Figure 1, A). At the end of the follow-up, the New York Heart Association functional class turned to $1.33 \pm 0.65$, with no difference between the groups, ascribable to correction of structural cardiopathy rather than presence of regular rhythm (Table 3; Figure 1,B).

The results show a great difference concerning the recurrence of $\mathrm{AF}$ as the control group is compared with the treatment groups (Table 4). The relative risk of AF development was 0.07 in the SPVI group $(P<.001 ; 95 \%$ confidence in- tervals [CI]: $0.02-0.27)$ and 0.195 in the Cox maze group $(P=.002 ; 95 \%$ CI: $0.07-0.56)$ as compared with the control group, thus evidencing a strong protective effect against $\mathrm{AF}$ recurrence. However, as the SPVI group was compared with the maze group in the prevention of AF recurrence, there was no difference between the groups (relative risk 0.358; $P=.215$; 95\% CI: 0.08-1.67).

Morbidity and mortality are listed in Tables 5 and 6 .

With regard to medication, the control group had the greatest percentage of patients receiving anticoagulants (Figure 2). Among all patients selected, amiodarone use at $1,12,24$, and 36 months was $33.3 \%, 40 \%, 38.6 \%$, and $41.9 \%$, respectively, and digoxin use at the same intervals was $50.9 \%, 49.1 \%, 47.7 \%$, and $54.8 \%$.

The analysis of thromboembolic or hemorrhagic events did not reveal any difference in the follow-up $(P=.059)$ (Figure 3), although patients in the control group did tend to have more events. By thromboembolic or hemorrhagic event, we mean any sign that is clinically perceived by the patient or that causes him or her damage, whether it is epistaxis, hematuria, digestive bleeding, petechiae, thrombosis of mechanical prosthesis, or ischemic or hemorrhagic CVA.

As a whole, the incidence of atrial flutter was low. This arrhythmia was more prevalent within the first 6 months, occurring only sporadically later in follow-up. One patient in the SPVI group had two episodes of atrial flutter at 2 and at 60 months. Two patients in the maze group and 2 patients in the control group, all of them at variable periods of time, had 12 episodes of the arrhythmia, all successfully treated with amiodarone.

\section{COMMENTS}

The maze procedure ${ }^{15}$ is considered to be the gold standard for comparisons ${ }^{24,25}$ of new emerging techniques for treating AF. However, wide acceptance of it has been difficult owing to its technical complexity. A number of modifications to the maze procedure have demonstrated a success rate of around $85 \%$ in the maintenance of sinus rhythm after valvular surgery combined with a procedure for $\mathrm{AF}^{26-28}$ These new techniques often use energy sources such as radiofrequency, ${ }^{29}$ ablation with microwaves,${ }^{30}$ or cryoablation. ${ }^{31}$ Energy source equipment for performing those techniques is often unavailable in many centers that are not referrals for arrhythmia surgery and add costs.

TABLE 4. Recurrence of AF according to technique

\begin{tabular}{lccccr}
\hline \multicolumn{1}{c}{ Group } & $\begin{array}{c}\text { PAF recurrence } \\
\text { (first event) }\end{array}$ & Patients/ mo & $\begin{array}{c}\text { PAF incidence } \\
\text { (per 100 pt-mo) }\end{array}$ & RR & 95\% CI* \\
\hline Control $(\mathrm{n}=20)$ & 14 & 366.00 & 3.83 & 1 & - \\
Maze $(\mathrm{n}=20)$ & 4 & 536.06 & 0.74 & .195 & $0.07-0.56$ \\
SPVI $(\mathrm{n}=20)$ & 2 & 749.50 & 0.26 & .070 & $0.02-0.27$ \\
SPVI vs maze & - & - & - & .358 & $0.08-1.67$ \\
\hline
\end{tabular}

$A F$, Atrial fibrillation; $P A F$, permanent atrial fibrillation; Patients/mo, the expected length of time in follow-up for one to develop the first atrial fibrillation episode; $R R$, relative risk; $C I$, confidence interval; SPVI, surgical pulmonary vein isolation. ${ }^{*}$ Cornfield analysis; $\dagger$ Fisher's exact test. 
TABLE 5. Morbidity according to surgical technique

\begin{tabular}{|c|c|c|c|}
\hline & SPVI (n) & Maze (n) & Control (n) \\
\hline \multicolumn{4}{|l|}{ Early morbidity } \\
\hline $\begin{array}{l}\text { Hemorrhagic CVA during } \\
\text { anticoagulation }\end{array}$ & 2 & 1 & \\
\hline Perioperative MI & 1 & & \\
\hline Bilateral pleural effusion & & 1 & \\
\hline Mediastinitis & & 1 & \\
\hline Immediate reoperation for bleeding & & 1 & \\
\hline $\begin{array}{l}\text { Late reoperation for mechanical } \\
\text { prosthesis }\end{array}$ & & 1 & 2 \\
\hline Transient ischemic accident & & & 1 \\
\hline Epistaxis & & & 2 \\
\hline Petechiae & & & 1 \\
\hline Hematuria & & & 1 \\
\hline Low GI bleeding & & & 1 \\
\hline Total & 3 & 5 & 8 \\
\hline
\end{tabular}

Since the pulmonary vein ostia were not manipulated in this series, we did not expect any cases of pulmonary vein stenosis, as confirmed by our follow-up.

Ectopic foci originating from the pulmonary veins can act as triggers and reinitiate chronic $\mathrm{AF},{ }^{19,27}$ and their ablation can prevent the reappearance of arrhythmia. The isolation of these foci, performed in the SPVI group, was perhaps the factor responsible for the favorable outcomes here described. There is a research line that claims that continuous $\mathrm{AF}$ does not depend on pulmonary veins for its induction or perpetuation $^{32}$ and that the mere isolation of pulmonary veins would only confine the trigger of intermittent $A F$. However, this was not observed in this series, where the results obtained regarding reversion to sinus rhythm were statistically similar between the group that received complete maze surgery and the one treated by SPVI. Inasmuch as the SPVI procedure does not involve incisions into the right atrium, cases of right atrial flutter postoperatively could be expected, and this occurred in few patients, reverting to sinus rhythm with amiodarone. Left atrial flutter prevention was achieved by adding the perpendicular mitral incision, as described in the Methods section. The study population consisted mainly of patients with rheumatic mitral disease, and this must be considered when discussing these results.

The control group was receiving more anticoagulant medication than the intervention groups during the follow-up,

TABLE 6. Mortality period and causes

\begin{tabular}{llcll}
\hline Group & Gender & Age $(\mathbf{y})$ & Postop. & \multicolumn{1}{c}{ Cause } \\
\hline SPVI & Female & 71 & Day 15 & ARF + septic shock \\
Maze & Female & 77 & Immediate & Tamponade + reoperation \\
Maze & Male & 73 & Day 57 & ARF + septic shock \\
Maze & Female & 65 & 20 mo & $\begin{array}{c}\text { Coronary artery dissection } \\
\text { during catheterization }\end{array}$ \\
\hline
\end{tabular}

SPVI, Surgical pulmonary vein isolation; $A R F$, acute renal failure.

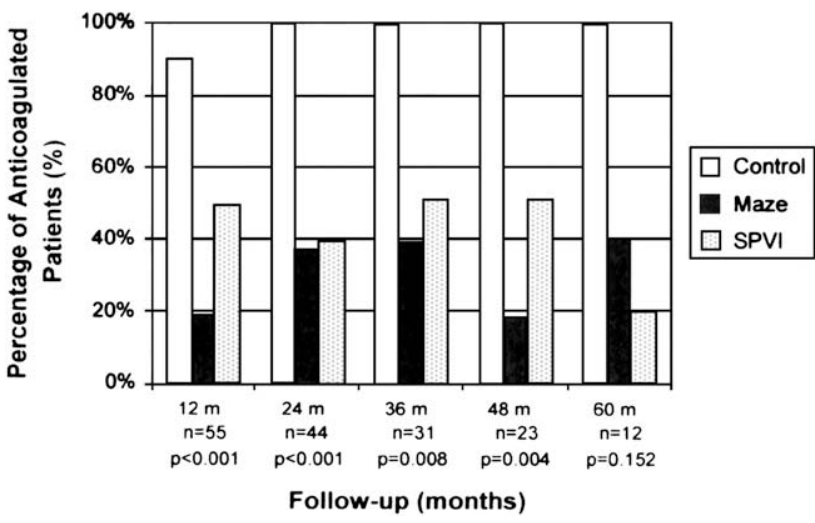

FIGURE 2. Percentage of anticoagulated patients as a function of treatment group at 12-month intervals.

and this did not mean reduction in the number of thromboembolic events, while maintaining the bias of being able to promote adverse hemorrhagic events. We cannot affirm that our hemorrhagic complications in this series are higher than our standards.

Our valvuloplasty techniques do not include mitral rings of any kind, because although they are widely available we favor nonsupported mitral annuloplasty both in rheumatic and in degenerative mitral valve insufficiency. We observed more cases of mitral insufficiency in the control group, and that could have led to more late reoperations.

From the clinical point of view, the patients in the three groups had significant improvement in functional class. However, this improvement was due to the correction of the valve lesion and occurred in similar fashion across the three intervention groups. As regards deaths, the complications presented might indirectly be ascribed to the surgery for AF, inasmuch as the longer time of ECC theoretically could be associated with greater complications postoperatively.

Many patients were admitted to the hospital with a recommended indication for treatment for AF, by maze or SPVI,

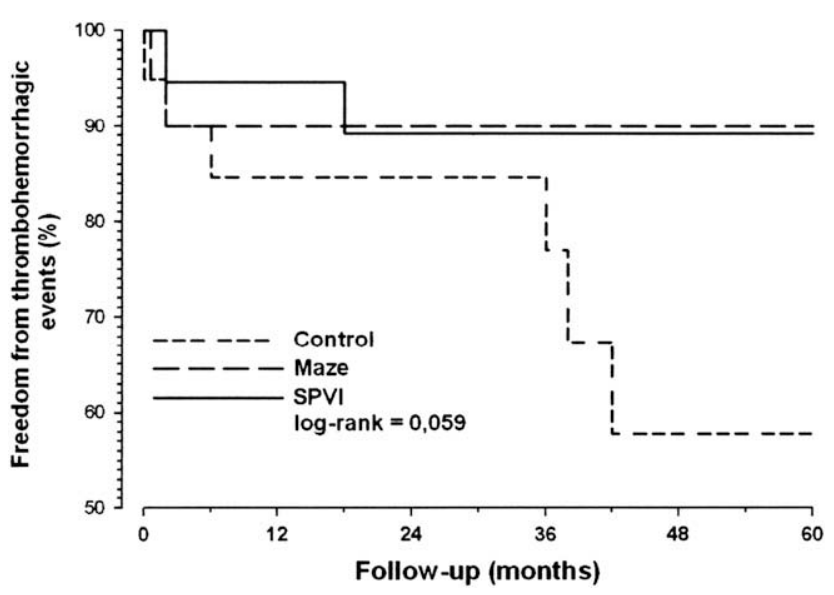

FIGURE 3. Kaplan-Meier curve showing the number of patients free from thrombohemorrhagic events as a function of time according to surgical technique. 
thereby being excluded from randomization. This might constitute a bias in selection. All patients without a specific recommendation were randomized so long as they fulfilled the inclusion criteria. As in the outpatient follow-up, the physician was aware of the group to which the patient belonged, and this may have constituted a treatment bias. All patients with AF were intensely treated so as to revert the arrhythmia to sinus rhythm, and this contributed to a greater reversion rate in the control group compared with that expected in the literature. ${ }^{12}$ Indeed, the patients in this study as a whole were subjected to a treatment package to revert $\mathrm{AF}$, which encompassed surgery itself, peroperative care, and strict follow-up in a dedicated outpatient clinic.

\section{CONCLUSIONS}

In conclusion, SPVI presented similar early and late restoration of sinus or atrial rhythm, as compared with the modified Cox maze procedure, without cryoablation, for $\mathrm{AF}$ associated with mitral valve disease in a predominantly rheumatic population. Both techniques were highly effective for rhythm restoration when compared with correction of the valve lesion alone. These results favor the adoption of SPVI as a preferable technique, simpler and equally effective in controlling AF. The results also can bring further information for understanding the mechanisms involved in chronic permanent $\mathrm{AF}$ origins and its treatment.

\section{References}

1. Go AS, Hylek EM, Phillips KA, Chang Y, Henault LE, Selby JV, et al. Prevalence of diagnosed atrial fibrillation in adults: national implications for rhythm management and stroke prevention: the AnTicoagulation and Risk Factors in Atrial Fibrillation (ATRIA) Study. JAMA. 2001;285:2370-5.

2. Feinberg WM, Blackshear JL, Laupacis A, Kronmal R, Hart RG. Prevalence, age distribution, and gender of patients with atrial fibrillation. Analysis and implications. Arch Intern Med. 1995; 155:469-73.

3. Wolf PA, Benjamin EJ, Belanger AJ, Kannel WB, Levy D, D'Agostino RB. Secular trends in the prevalence of atrial fibrillation: The Framingham Study. Am Heart J. 1996;131:790-5.

4. Benjamin EJ, Wolf PA, D'Agostino RB, Silbershatz H, Kannel WB, Levy D. Impact of atrial fibrillation on the risk of death: the Framingham Heart Study. Circulation. 1998;98:946-52.

5. Petersen P, Godtfredsen J. Embolic complications in paroxysmal atrial fibrillation. Stroke. 1986;17:622-6.

6. Nattel S, Hadjis T, Talajic M. The treatment of atrial fibrillation. An evaluation of drug therapy, electrical modalities and therapeutic considerations. Drugs. 1994; 48:345-71.

7. Petersen P, Boysen G, Godtfredsen J, Andersen ED, Andersen B. Placebo-controlled, randomised trial of warfarin and aspirin for prevention of thromboembolic complications in chronic atrial fibrillation. The Copenhagen AFASAK study. Lancet. 1989;1:175-9.

8. Shivkumar K, Jafri SM, Gheorghiade M. Antithrombotic therapy in atrial fibrillation: a review of randomized trials with special reference to the Stroke Prevention in Atrial Fibrillation II (SPAF II) Trial. Prog Cardiovasc Dis. 1996;38:337-42.

9. Singer DE, Hughes RA, Gress DR, Sheehan MA, Oertel LB, Maraventano SW, et al. The effect of aspirin on the risk of stroke in patients with nonrheumatic atrial fibrillation: The BAATAF Study. Am Heart J. 1992;124:1567-73.

10. Connolly SJ, Laupacis A, Gent M, Roberts RS, Cairns JA, Joyner C. Canadian Atrial Fibrillation Anticoagulation (CAFA) Study. J Am Coll Cardiol. 1991;18: 349-55.
11. Newman D, Gillis A, Gilbert M, Dorian P. [Long term drug therapy for the prevention of recurrence in atrial fibrillation] [In French]. Can J Cardiol. 1996 Feb; 12(Suppl A):21A-6A.

12. Kalil RA, Maratia CB, D'Avila A, Ludwig FB. Predictive factors for persistence of atrial fibrillation after mitral valve operation. Ann Thorac Surg. 1999;67: 614-7.

13. Bando K, Kobayashi J, Hirata M, Satoh T, Niwaya K, Tagusari O, et al. Early and late stroke after mitral valve replacement with a mechanical prosthesis: risk factor analysis of a 24-year experience. J Thorac Cardiovasc Surg. 2003;126: 358-64.

14. Kalil RA, Nesralla PL, Lima GG, Leiria TL, Abrahao R, Moreno P, et al. Assessment of thromboembolism after the Cox-Maze procedure for chronic atrial fibrillation secondary to mitral valve lesion. Arq Bras Cardiol. 2002; 78:374-81.

15. Cox JL. The surgical treatment of atrial fibrillation. IV. Surgical technique. $J$ Thorac Cardiovasc Surg. 1991;101:584-92.

16. Prasad SM, Maniar HS, Camillo CJ, Schuessler RB, Boineau JP, Sundt TM 3rd, et al. The Cox maze III procedure for atrial fibrillation: long-term efficacy in patients undergoing lone versus concomitant procedures. J Thorac Cardiovasc Surg. 2003; 126:1822-8.

17. Kalil RA, Albrecht A, Lima GG, Vasconcellos D, Cunha B, Hatem D, et al. Results of the surgical treatment of chronic atrial fibrillation. Arq Bras Cardiol. 1999 73:139-48.

18. Gregori F Jr, Cordeiro CO, Couto WJ, da Silva SS, de Aquino WK, Nechar A Jr Cox maze operation without cryoablation for the treatment of chronic atrial fibrillation. Ann Thorac Surg. 1995;60:361-3; discussion 364.

19. Fieguth HG, Wahlers T, Borst HG. Inhibition of atrial fibrillation by pulmonary vein isolation and auricular resection-experimental study in a sheep model. Eur J Cardiothorac Surg. 1997;11:714-21.

20. Haissaguerre M, Jais P, Shah DC, Takahashi A, Hocini M, Quiniou G, et al. Spontaneous initiation of atrial fibrillation by ectopic beats originating in the pulmonary veins. $N$ Engl J Med. 1998;339:659-66.

21. Kalil RA, de Lima GG, Abrahao R, Albrecht A. Simplified surgical technique for the treatment of chronic atrial fibrillation in patients with mitral valve disease: could it work? Rev Bras Circ Cardiovasc. 2000;15:129-35.

22. Kalil RA, Lima GG, Leiria TL, Abrahao R, Pires LM, Prates PR, et al. Simple surgical isolation of pulmonary veins for treating secondary atrial fibrillation in mitral valve disease. Ann Thorac Surg. 2002;73:1169-73.

23. de Lima GG, Kalil RA, Leiria TL, Hatem DM, Kruse CL, Abrahao R, et al. Randomized study of surgery for patients with permanent atrial fibrillation as a result of mitral valve disease. Ann Thorac Surg. 2004;77:2089-94; discussion 2094-5.

24. Cox JL. Atrial fibrillation II: rationale for surgical treatment. J Thorac Cardiovasc Surg. 2003;126:1693-9

25. Stulak JM, Dearani JA, Sundt TM 3rd, Daly RC, McGregor CG, Zehr KJ, et al. Superiority of cut-and-sew technique for the Cox maze procedure: comparison with radiofrequency ablation. J Thorac Cardiovasc Surg. 2007;133:1022-7.

26. Kosakai Y, Kawaguchi AT, Isobe F, Sasako Y, Nakano K, Eishi K, et al. Cox maze procedure for chronic atrial fibrillation associated with mitral valve disease. J Thorac Cardiovasc Surg. 1994;108:1049-54; discussion 1054-5.

27. Tuinenburg AE, Van Gelder IC, Tieleman RG, Grandjean JG, Huet RC, van de Maaten JM, et al. Mini-maze suffices as adjunct to mitral valve surgery in patient with preoperative atrial fibrillation. J Cardiovasc Electrophysiol. 2000;11:960-7.

28. Geidel S, Ostermeyer J, Lass M, Boczor S, Kuck KH. Surgical treatment of permanent atrial fibrillation during cardiac surgery using monopolar and bipolar radiofrequency ablation. Indian Pacing Electrophysiol J. 2003;3:93-100.

29. Chiappini B, Martin-Suarez S, LoForte A, Arpesella G, Di Bartolomeo R, Marinelli G. Cox/Maze III operation versus radiofrequency ablation for the surgical treatment of atrial fibrillation: a comparative study. Ann Thorac Surg. 2004;77 87-92.

30. Maessen JG, Nijs JF, Smeets JL, Vainer J, Mochtar B. Beating-heart surgical treatment of atrial fibrillation with microwave ablation. Ann Thorac Surg. 2002; 74:S1307-11.

31. Manasse E, Gaita F, Ghiselli S, Barbone A, Garberoglio L, Citterio E, et al. Cryoablation of the left posterior atrial wall: 95 patients and 3 years of mean followup. Eur J Cardiothorac Surg. 2003;24:731-40.

32. Cox JL. The central controversy surrounding the interventional-surgical treatment of atrial fibrillation. J Thorac Cardiovasc Surg. 2005;129:1-4. 